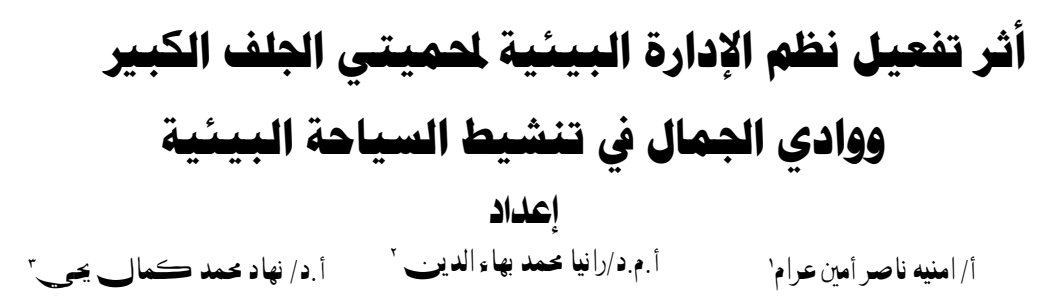

\title{
טגil|
}

تهدف الدراسـة إلى تسليط الضوء على أثر تفعيل نظم

الإدارة البيئية لمحميتي الجلف الكبير ووادي الجمال فى تنشيط

السياحة البيئيـة، وتعتمد الدراسـة على الأسـاليب الإحصائية لدراسـة

متغيرات الدراسـة مـن خلال استعراض الدراسـات النظريـة المتعلقة

بموضوع الدراسـة ، وكذلك إجراء الدراسـة الميدانية من خلال

المقابلات الشخصية ، حيث تم تصميم ثلاث استهمارات استبيان ،

وجهت الأولى إلى مديري محميتي الجلف الكبير ووادي الجمال ،

ووجهت الثانية إلى الخبر اء السياحيـين ، ووجهت الثالثة إلى الخبر اء

البيئيسين، وذلك بغرض التعرف على توجهاتهم وآرائهم نحو أبعاد

الدراسـة. وتوصلت الدراسـة إلى أن نظم الإدارة البيئيـة بالمحميتـين

تتبنى سياسـة بيئية مناسبـة، وتتضهمن الالتزام بالحد من التلوث،

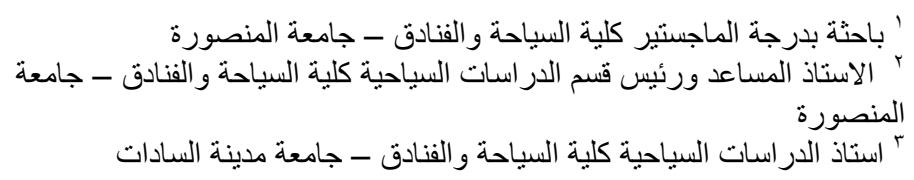


وذلك من خلال تطبيق القوانين واللوائح والنظم البيئية الصـادرة بالقوانين والتشريعات الخاصدة بالحفاظ على البيئة والمصادر الطبيعية ومنـع التلوث بأنواعه المختلفة وتنفيذها ، مها يؤدي إلى تنشيط السياحة البيئية بالمحميتين.

وتوصي الدراسـة بضرورة تشجيع التعاون مـع الجهات البحثية العالمية والجهات المانحة فى إجراء دراسات بيئية بهواقع المحميات، وتزويد المحميات بالأجهزة والمعدات التي تسهم فى عملية الرصد البيئي لمناطق السياحة البيئية ومعامل التقييهم والدراسـة. الكلمات الدالة: نظم الإدارة البيئية - السياحة البيئية محمية الجلف الكبير - محمية وادي الجمال .

\section{The Impact of Environmental} Management of AL Gilf Al-Kabeer and Wadi A-Gamal Reserves on Activating Environmental Tourism

\section{Abstract}

This study aims to shed light on the impact of the environmental management systems of the two reserves of Gilf El Kabir and Wadi El Gemal in stimulating ecotourism. The study relies on the descriptive and analytical approach by reviewing theoretical studies related to the subject of the study, as well as conducting the field study through personal interviews. Where three questionnaire 


\section{مجلة كلية السياحة والفنادق - عدده- يونيو اr.r P P}

forms were designed, the first was directed to the directors of the two reserves of Gilf al-Kabir and Wadi al-Jamal, the second was directed to tourism experts, and the third was directed to environmental experts, in order to identify their views and opinions about the dimensions of the study.

The study found that the environmental management systems in the two reserves adopt an appropriate environmental policy, and include commitment to reduce pollution, through the application and implementation of laws, regulations and environmental systems issued by laws and legislations for the preservation of the environment and natural resources and the prevention of various types of pollution, which leads to the revitalization of ecotourism in the two reserves.

Keywords: Environmental Management AL Gilf Al-Kabeer, Wadi A-Gamal , Environmental Tourism .

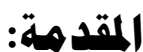

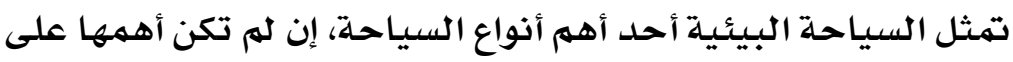

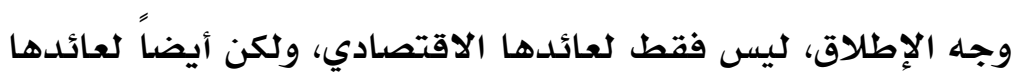

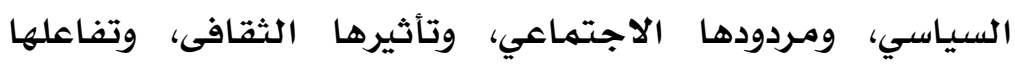


أر تفعيل نظم الإدارة البيئية لمحميتي الجلف الكبير

ووادي الجمال بـ تنشيط السياحة البيئية

الإنساني، والحضاري، فهى سياحة متعددة الجوانب، ممتدة الأبعاد

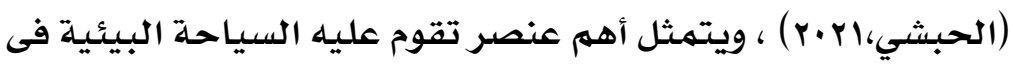
عدم إحداث الإخلال بالتوازن البيئي الناتجة عن تصرفات الإنسان والتي تكون متمثلة بِّ تصرفات السائح فى حالة السياحة البيئية، وما قد يحدثه من تلوث فيه؛ نتيجة لذلك ازداد أهتمام كافة المنظمات الدولية، أبتداء من منظمة السياحة العالمية، ومجلس السفر والسياحة العالمي، بالإضافة إلى المنظمات الحكومية، والمنظمات الجماهيرية غير الحكومية المهتمة بالسياحة والبيئة (داود . (r.r. . وتشمل نظم الإدارة البيئية مجموعة من العمليات والممارسات التى تمكن منظمة ما من تخفيض آثارها البيئية السلبية وزيادة كفاءتها التشغيلية، وهو أداة لتحسين الأداء البيئي، ويشمل الهيكل، التنظيم، والتخطيط، والموارد التلازمة لوضع سياسة للحماية البيئية وتنفيذها ورعايتها، ويوفر مثل هذا النظام الاتساق للمنظمات كى تستجيب للظروف البيئية عن طريق تخصيص الموارد، وتفويض المسؤلية،

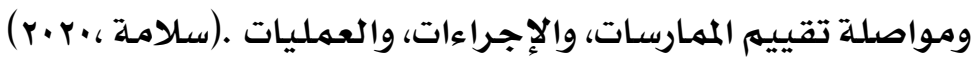

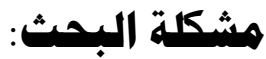

تُواجه المحميات الطبيعية يٌْ مصر تعديات وتحديات مختلفة تؤثر عليها وتهدد قيمتها السياحية و خصوصا محميتي وادي الجمال والجلف الكبير، ومن أهم تلك التعديات: الاستخدام غير المنظم 
للمناطق الساحلية، وعمليات تغيير خط الشاطئ، واحتمالات التلوث والأنشطة السياحية والتعدينية غير الرشيدة، والصيد والرعي الجائر وقطع الأشجار، والتفحيم، بالإضافة إلى الإضرار بالتراث الثقايِ والحضاري الناتج عن عبث السكان المحليين والزائرين الأجانب بالكتابة على الصخور وإزالة النقوش ( البعقوبي ، V. V ) و ولأن قياس وتقييهم دور الإدارة البيئية بالمحميات الطبيعية يهدف إلى التخلص من تلك التعديات على المحميات، وضمان نشاطها واستمـراريتها من خلال ما يسهى بالأداء المستدام، لذا فإن تفعيل دور الإدارة البيئية بشكل خاص لمحميتي الجلف الكبير ووادي الجمال سيساهم بشكل فعال فى تنشيط السياحة البيئية بالمحميتين.

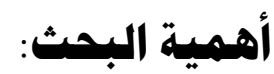

ترجـع أهمية دراسـة إلي أثر تفعيل نظم الإدارة البيئيـة بـالمحميتين محل الدراسـة، والتى سيترتب عليها عديد من المزايا أهمها : تنشيط السياحة البيئية بالمحميتين، ومنـع التلوث البيئي، وتحلديد الظروف البيئية التى تساعد على الالتزام البيئي و تعظيهها، وتحويل البيئة إلى فرصدة للاستثهـار السياحي مـ الحفاظ على الثروات الطبيعية، وتطوير نظم إدارة المحميتين، والتحسين المستهر للأداء البيئي للهحميتين. 
أر تفعيل نظم الإدارة البيئية لمحميتي الجلف الكبير

ووادي الجمال يُ تنشيط السياحة البيئية

$$
\text { تقوم هذه الدراسة على تحقيق عدد من الأهداف: }
$$

ا ـ التعرف على مـاهية الإدارة البيئية وأهميتها والمتطلبات

العامـة لتطبيقها.

r · دراسـة العلاقة بين الإدارة البيئية وتنشيط السياحة

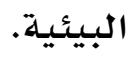

r. التعرف على القوانين والتشريعات البيئية التى تتبعها

المحميات الطبيعية يف المحافظة على حقوقها ضد عمليات التعدي

$$
\text { عليها . }
$$

ع. التعرف على النتائج الإيجابية التي تظهر من خلال

تفعيل الإدارة البيئية ، وأثر ذلك على تنشيط السياحة البيئيـة

$$
\text { بالمحميتين مححل الدراسـة. }
$$

\section{فرضيسة البحث:}

تم صياغة فروض الدراسلة على النحو الآتي:

الفرضيـة الأولي : لا يوجد علاقة ذات دلادة إحصائية بين

تفعيل نظم الإدارة البيئية وبين تنشيط السياحة البيئية فى

$$
\text { محمية الجلف الكبير - مهن }
$$

الفرضية الثانية : لا يوجد علاقة ذات دلانة إحصائية بين

تفعيل نظم الإدارة البيئية وبين تنشيط السياحة البيئية ـية

$$
\text { محميـة وادى الجمال. }
$$

\section{همددات الندراسة:}


المحددات المكانية: تتهثل فى محميتى الجلف الكبير ووادى

الجمال المال

المحددات الزمنية: تم توزيع استهمارات المقابلة الشخصية

$$
\text { فى الفترة من أغسطس إلى نوفمبر 19 •r. }
$$

المحددات البشريـة: تم عمل مقابـات شخصصية مـع: مديري

المحميتين - خبراء ِِّ مجال السياحة - خبراء فِّ مجال

$$
\text { البيئة . n }
$$

\section{الاطار النظرى للدراسة : \\ أولاً : الإدارة البيئية : \\ 1 المفهوم الإدارة البيئية :}

هي عملية إداريـة متكاملة تتحقق من خلال الالتزام والاقتتناع

التام بتطبيقها للوصول إلى التتهية المستدامة لكافة القطاعات

الاقتصادية،كهما تحقق هذه الإدارة الإنتاج الأنظف، والحد من

التلوث الناتج عن النشاط الصناعي، والزراعي، والسياحي،

والتجاري، والخدمي بما يضهن رفاهية الأجيال الحالية

والمستقبليةت(البزي ، 10 •r) ). 
أر تفعيل نظم الإدارة البيئية لمحميتي الجلف الكبير

ووادي الجمال يُ تنشيط السياحة البيئية

كما عرفها ابن آدم( 10 · ب) بأنها " إدارة للهنظمة لتبقى واعية

لتفاعلات سلعها وأنشطتها مـع البيئة، وذلك لغرض الإنجاز والتحسين المستهمر لمستوى الأداء المرغوب .

Y

• تعمل الإدارة البيئية على تحقيق التوازن بين إمكانية النهمو

المستقبلي والحفاظ على جودة الحياة وتحسينها على المدى

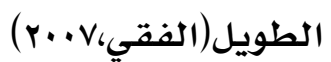

• تعد الإدارة البيئية كياناً تنظيهياً مهماً وأساسياً بالنسبة النسية لكل تنظيهم حكومي أو خاص على السواء وذلك لنأسباب الآتية التى

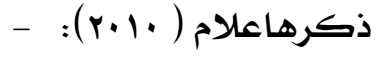

•تزايد المشاكل البيئية فى عديد من مناطق العالم، والتى أصبـحت تشكل خطراً فعلياً على حياة الإنسـان وغيره من الكائنات الحيةة، والتى تحتهم الاستجابة السريعة لمواجهتها على مستوى

$$
\text { مؤسسي منظم( دهيهي وبروث ، . + r) . }
$$

•وجود الاضطرابات البيئية فى التوازن البيئي العالمي، وغيره من المشاكل البيئية التى يمتد أثرها لأكثر من دولة أو إقليم أحيانا،

والتى تستوجب إنشاء منظمات خاصة وعلى مستوى عالمي، وذات

خبر ات واختصاصات معينة لمعالجتها (Manr,2010 ).

• الاستغلال الجائر لعديد من الموارد البيئية بشكل أدى إلى فناء بعض تلك الموارد، مها استدعى التحرك لمعالجة هذا الوضع على 
مستوى تنظيهي واسـع لتنظيهم استعمال هذه الموارد، والعمل على إدامتها للأجيال القادمة)(Pandy,2007). • تأمـين الاستـدامة للموارد الطبيعية بترشيد استهلاك هذه الموارد ، بالإضافة للطاقة وما لها من تأثير اقتصدادي ايجـابي على كل من المدى القريب والبعيد، بها يضهن النهماء الاقتصـادي والاجتماعي للدولة والذى ينعكس إيجابياً على رفاهية أفرادها. • الحفاظ على البيئة من التلوث وذلك لخفض الآثار السلبية على البيئة، وبوجود الإدارة البيئية التي تعهل علي تخفيض هذه الآثار

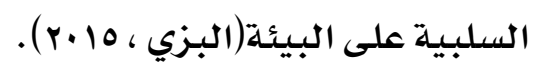

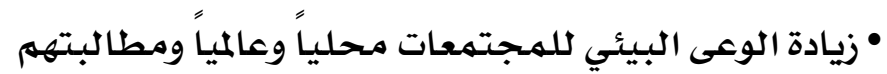
المستهـرة بحل المشاكل البيئية، وكذلك زيادة الضغوطات الممارسـة من قبل المنظمات البيئية غير الحكوميـة على المستويين المحلي والعالمي، ومطالبتها للحكومات بلعب دورها فى هذا

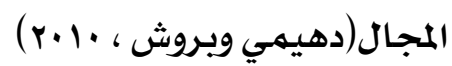

\section{ثاثيا: نظم الإدارة البيئية}

مفهوم نظم الإدارة البيئية :

عرفها ( Grandoit 2005 ) على أنها مجهموعة من السياسـات والمفاهيه والإجراءات والالتزامات وخطط العمل التى من شـأنها منـع حلدوث عناصر التلوث البيئي بأنواعه، وتفهم العاملين لذلك النظام كل فى اختصاصده، هذا بالإضافة إلى تطبيق هذه الأساليب 
أر تفعيل نظم الإدارة البيئية لمحميتي الجلف الكبير

ووادي الجمال يـ تنشيط السياحة البيئية

والإجراءات فى الواقع العملي وإعداد التقارير الدورية عن نتائج

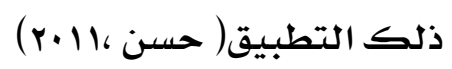

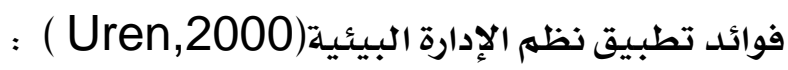

$$
\text { r. r. r. تحسين الأداء البيئي. }
$$

ه . تحقيق ميزة تنافسية .

7 . خفض تأثيرات المنتجات على البيئة والصحة والسلامة طوال

$$
\text { دورات حياتها. }
$$

v. زيادة الفعالية، وتقليل التكاليف .

^. جذب عملاء جلدد ودخول أسواق جديلدة.

$$
9 \text { ـ زيادة درجة ولاء العميل . }
$$

• ا ـ تحقيق الوعي لدى العاملين بهسؤولياتهم تجاه القضية البيئية 11 ـ الحقيق الجودة المطلوبة فى البر امـج التى يتهم تنفيذها.

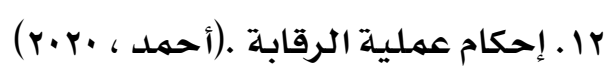

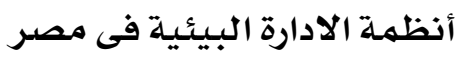

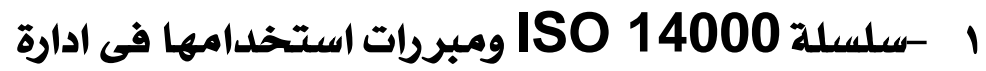

المحميات الطبيعية 
هى سلسلة مواصفات قياسية دولية خاصدة بنظم الإدارة البيئية تتكون من عدد من المواصفات، تتهـحور حول كل واحدة منهها مجموعة من البنود والمتطلبات ذات الطابع الفني والادارى، والغاية منها تشجيع وتنهية ادارة سياحية بيئية أكثر كفاءة وفاعلية فى المحميات الطبيعية فى اتجاه تطوير البيئة السياحيـة( إبراهيهم ،

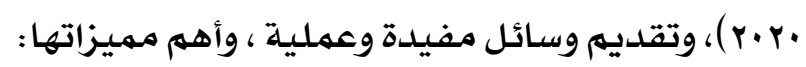
- فاعليـة الادارة البيئية فى المواقع السياحية.

-توفير أسـاس صحيح فى توجيه الحركة السياحية (الطاقة الاستيعابية).

-توفير تنمية سياحية مستدامة فى المحميات الطبيعية. وهى بذلك تعبر عن التزام إدارة مواقـع المحميـات الطبيعية بأداء دور فاعل فى تفحص عملياتها بشكل شـامل، مـع دمجها مـع الاعتبـارات البيئية والسياحية، والبحث عن وسـائل لزيادة فاعلية العمليات، و إقامـة الدراسـات الكفيلـة للحد من إلحاق الضـرر بمواقع السياحلة البيئية فى مرحلة مبكرة من مراحل دورة حياة الموقع السياحى، والبحث عن فرصدة لتحويل منتتجاتها الثانوية غير المطلوبة إلى مواد يهكن إعادة استخدامها، وبها يقدم للسـائحين والجهات ذات العلاقة بالقضايا البيئية ضهمانات تعزز الثقة بها وبالخدمات السياحية

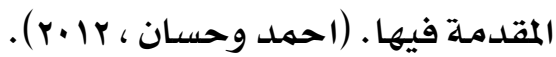

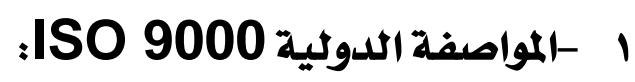


أر تفعيل نظم الإدارة البيئية لمحميتي الجلف الكبير

ووادي الجمال بـ تنشيط السياحة البيئية

تمثل أداة لنقل التقنية الخاصدة بأفضل التطبيقات المتاحة بالإدارة النوعيلة، والنتيجهة النهائية التى تسعى نحوها هذه السلسلـة هى تطوير الأداء البيئي فى المحميات الطبيعية، ويجرى التأكيد عالمياً على هذه السلسلة كونها تهثل مصدرا مـرشدا نحو تبنى نظام فاعل لإدارة البيئة فى المحميات الطبيعية ، والقائم على مجمهوعة

متطلبـات متسلسلـة ملزمـة التطبيق والتوافق ترتبط مـع بعضها البعض بصورة متكاملة مـن أجل تحقيق الهدف الاساسى للسلسلـة، ويقوم الطرف الثالث المحايد (هيئة مستقلة للتقييهم ومنح الشهادة)

بتقييه المحمية الطبيعية للحصول على شهادة بالسلسلة

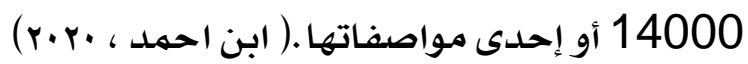
تطبيق نظم الإدارة البيئية يِ السياحة تتميز العلاقة بين السياحة والبيئة بالتبادلية والتداخل ونجاح المثـاريـع الاستثماريـة ، فالسياحة كانت نتاجـا لتفاعلها مـع البيئـة ، حيث الأماكن الجذابة والمناظر الطبيعية والمناخ المعتدل كل ذلك

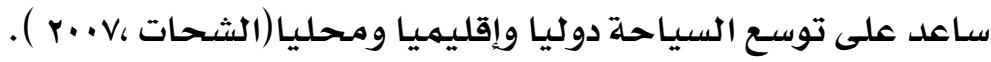
هذا ؛ وقد اهتم خبر اء السياحة بـالأثر المتبـادل بين السياحة والبيئة ، ومـع تدفق أعداد السـائحين بأعداد كبيرة للهواقع السياحية، واهتهمام السائحين بالتنوع الحيوي، جرى تخريب وتدمير عديد من البيئات وتهديد للحياة الفطرية، ولذلك بلدأت تتعالى الأصوات بضرورة اهتمـام السياحة بالأمور البيئية. وتبـين أنه لا يهكن الحفاظ 
على البيئة إلا بإشـراك السكان المحليين يِ المحافظة عليها

$$
\begin{aligned}
& \text { ورعايتها (محمدد ،0... r. ) ) } \\
& \text { ثالثاً :السيياحة البيئية } \\
& \text { مفهوم السياحة البيئية : }
\end{aligned}
$$

يعبر مصطلح السياحلة البيئية عن نوع جديد من النشاط السياحى الصديق للبيئة الذى يهارسـه الإنسـان مححافظاً على الميراث الفطري الطبيعي و الحضاري للبيئة( زهير ، 1 · ب)، السياحة البيئية عبارة عن زيـارات مسئولة بيئيـا لمناطق طبيعية غير مهلددة إلى حد ما بغرض التمتع بالطبيعة ودراستها وتقديرها ، بالإضـافة إلى أى مزارات ثقافية مصـاحبة سواء من الماضي أو الحاضـر ، وتعهل

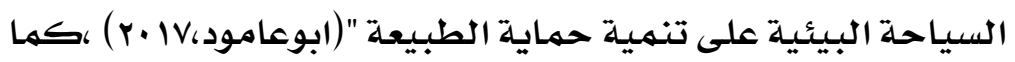

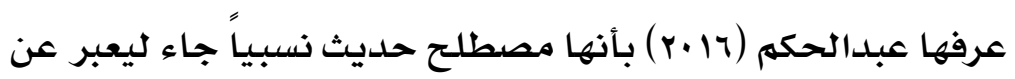
نهط جديد مـن النشاط السياحي الصديق للبيئة الذى يهـارسـا الإنسان محافظا على الميراث الفطري الطبيعي والحضاري للبيئة التى يعيث فيها ويهارس نشاطه وحياته ،وقد تكون يِّ أبسط صورها كارتياد الصحراء للتمتع بجمالها وطبيعتها بها فيها من حياة فطرية نباتية وحيوانية ومهارسسة كافة الأنشطة المعتادة فيها أو للسياحة يِ المدن السـاحلية والمناطق الأثريـة أو المناطق الجبلية لجمال طبيعتها ولبرودة طقسها واعتدال مناخها، وقد تكون سياحة البحر للنزهة والاستهتاع بالصيد وللكثف عن ما يِّ أعماقه من 
أر تفعيل نظم الإدارة البيئية لمحميتي الجلف الكبير

ووادي الجمال بـ تنشيط السياحة البيئية

كائنات بحرية فريدة وشعاب وأحجار مـرجانية نادرة قلما توجد ِِ

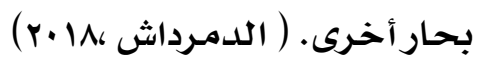

أهمية السياحة البيئية:

تهثل السياحة البيئية اتجاها جديدا للتطور الديناميكي ِِِ صناعة السياحة، وهي لا تفهم دائما وِِِ كل مكان بشكل واحد ، وتغلغلت إلى مـالات النشاط السياحي المختلفة، وهي غير مححدودة ضهن أطر وتعاريف صارمـة، وتعد السياحة البيئية شعارا لسياحة المحميات الطبيعية للحفاظ على الموارد الطبيعية من استثمار الطبيعة بالشكل الأمثل( فرحي،م ·.ץ) . والسياحة البيئية تتعلق بتحقيق قواعد السياحة الدائمةلة وحماية البيئة ِِِ المقصد بشكل خاص، وتشهل على سياحة الغابات الطبيعية والجبال والكهوف والينابيع والصحراء والشواطئ ، وهي تمارس عبر وضع قواعد سلوكية وتعليمات يلتزم بها السـائح للحفاظ على البيئة من جهة، ومـن جهة أخرى ليكون المقصد صـالحا للزيارة، وتشكل السياحة البيئية مصدرا مهما للتنمية الاقتصادية ِِّ البلدان والقرى وداخل الغابات للقطاع

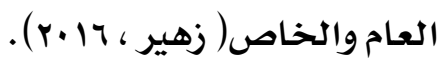

وتعد السياحة البيئية اليوم من أهمر الأنشطة السياحية عالميا لما تحققه من تنميلة دائمة للموارد الطبيعية وحماية للهمجتمعات

$$
\text { المحلية ِِّ المنطقة (العجيلى ، با •r). }
$$


وهي عبارة عن مجموعة من نشاطات تهدف جميعها إلى المحافظة على الموروثات الطبيعية، والحضارية، وتكمن أهمية السياحة البيئية ِِخ كونها سياحة رفيقة بالبيئة وتعتمد بشكل أساسي على(Ajlouni,2011) :

ا .العوامل الطبيعية الإيكولوجية: وتضهم العناصر والأنظمة

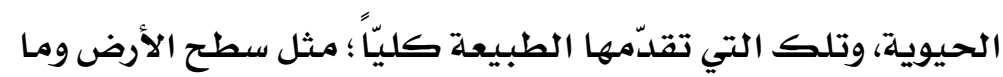
عليه من جبال ووديان وغابات ومغاور وأنهار ومحمهيات وصحارى، وأنواع المشاهدات والخبر ات الواسعـة المتضهنـة فيها، أو التي عمل عليها الإنسان مثل الحدائق والمنتزهات. r . العوامل المناخيةة: أي الفصول المناخية ومـا تقدّمهـ مـن عناصر وإمكانات وتحوّلات يْ الصيف أو الشتاء، ِِ الربيـع أو الخريف، وبحيث تتحوّل هذه العناصر الى مكوّنات سياحية كبرى ؛ من مشاهدة الغروب على شـاطىء البحر أو مهارسـة التزلج على الثلج ، أو السهر مـع النجوم يِ الصحراء بعيدًا عن كل إنارة. r. العوامل البيولوجيةة: مثل الثروات النباتية المتتوعة ؛ من أزهار، وأشجار، ونباتات، ومياه معدنية، إلى الثروة الحيوانية والسمكية، من طيور وأسهاك وكائنات بحرية وبريـة مختلفة. وترتبط السياحة البيئية بالحضارة والثقافة والعادات والتقاليد ارتباطاً وثيقا من خلال الأهمية الثقافية للسياحة البيئية القائممة على نشر المعرفة وزيـادة تأثير المعرفة على تطوير وتقديهم البر امـج 
أر تفعيل نظم الإدارة البيئية لمحميتي الجلف الكبير

ووادي الجمال بـ تنشيط السياحة البيئية

السياحية البيئية ونشر الثقافة المحافظة على البيئة والمحافظة على الموروث والتراث الثقايِّ الإنساني، وثقافة الحضارة والمواقع التاريخية، وصناعة الأحداث والمناسبات الثقافية والعمل على الاستفادة من الثقافة المحلية مثل الفنون الجميلة والآداب والفولكلوروسياحة الندوات واللقاءات الثقافية.( عبدالباسط ،.r.r )

\section{أثكال السياحة البيئية ِِِ مصر}

تُعد السياحة البيئية سوقاً واعدة عالمياً ، لم تجن مصر منها حتي الآن مـا يتناسب مـع إمكاناتها مـن تراث طبيعي وحضاري وثقايِ

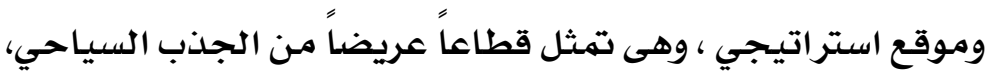
ومن أشكال السياحة البيئيـة فى مصر : -

ا ـ الغوص بالأجهزة وآلات التصوير تحت الماء فى الأماكن التى تنفرد بأنواع الشعاب المرجانية والأحياء المائية المختلفة فى البحر الأحمر والجزر المنتشرة فى المياه الإقليمية المصرية(كمال ،و . بـ). r ـ مشاهدة غابات المانجروف لتكاثر أنواع الطيور البحريـة فى البحر الأحمر وخليجي السويس والعقبـة.( عيسى، • +r)

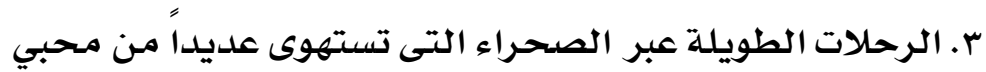
المغامـرة لزيارة بيئات متعدددة فى الصحرراء الغربية مثل بحر الرمال

الأعظم وهضبـة الجلف الكبير ومنطقة العوينات التى تقوم بها (بهـ

$$
\text { محهد ومهاهد ، ع أ.r) ). }
$$


ع ـ صيد الحيوانات البرية مثل بعض الزواحف والثدييات الصغيرة المسموح بصيدها طبقاً لتعليمات سنوية توضح عدد ونوعية وأوقات

$$
\begin{aligned}
& \text { الصيد( طلحي والرمـيدي ، 11 •r). }
\end{aligned}
$$

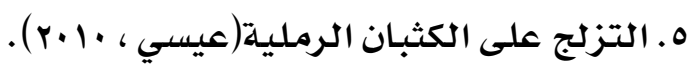

7. مارثون الصحراء وراليات الصحراء المقننة، سباق الهجن، الخيول،

سباق الحمام، العلاج بالخامات الطبيعية( محمود ، 17 . r). V. سياحة المحميات الطبيعية والتي يطلق عليها السياحة الفطرية

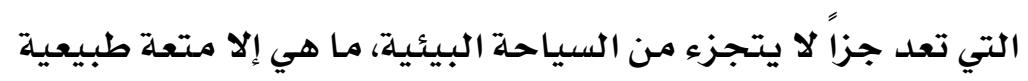
بها يوجد من حولنا يِ البيئة البرية والبحرية، وهذا يعني كيفية توظيف البيئة التي حولنا لكي تمثل ثهطاً مـن أنهاط سياحة

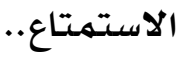
1. سياحة المزارع: أو ما يسهى بالسياحة الريفية، وفيها يتجه السـائح إلى الريف لوجود عوامل جذب سياحية تنبـع من البساطة يِ حياة الريف ؛ من هدوء وأعمال زراعيـة. 9.السياحة الخضراء يِّ السهول، والغابات، والمنتزهات، وحدائق

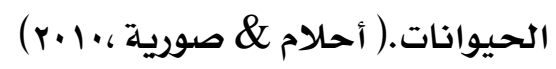
• . استكشاف الجبال والوديان، وإقامـة المعسكرات والمخيهات 11 . سياحة المنتجعحات السياحية والمعسكرات الصيفية والكثفية . r ا .سياحة الآثار والنقوش والمغارات الأثرية ، وتحليل الصخور

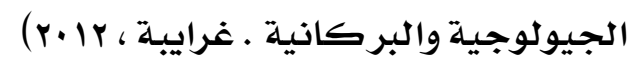


أر تفعيل نظم الإدارة البيئية لمحميتي الجلف الكبير

ووادي الجمال بِ تنشيط السياحة البيئية

هذا ؛وتبرز الأنواع السـابقة للسياحة البيئية سواء المرتبطة

بالطبيعة، أو التراث، أو الغرض الذي ارتبط بها وفق مفهوم تزايد انتقال الإنسان يْ إطار محيطه البيئي الطبيعي والتراثي للاستهتاع وإثباع رغبته لما تحويـه هذه السياحة من مقومات طبيعية، وثقافيـة،

وتراثية يفخر بها الإنسـان عبر الأجيال السـابقة، ويتعلهم منها

مستقبـلا، وِيْ الوقت ذاته ليستمتحع بجمال الطبيعة، وفطرتها يِ إطلار الهروب مـن ملوثات، وضغوط، ومضاعفات الحيـاة الماديـة وأمراضها الاجتهماعية.( دراركة وآخرون ، عابـr) المحميات الطبيعية ف2 مدر (محمية الجلف الكبير فى الوادي الجمليل ومحمية وادى الجمال فى البحر الأحمر): أولاً: محمية الجلف الكبير بمحافظة الوادي الجديل إن الهدف من إعلان تلك المحمية محمية طبيعية يتركز فى اونى الحفاظ على النظم البيئية للصحارى من أجل الأجيال المستقبلية، وحماية الموارد الثقافية والأثرية بالمنطقة، وتثجيع الاستخدام المستدام لتلك الموارد من خلال إنشاء نظام إدارة سليهم ، وتعظيهم الفوائد الاقتصادية والاجتماعية المستدامـة للموارد الطبيعية من خلال جذب السياحة البيئية، وتوفير فرص عمل لسكان المناطق القريبـة من المنطقة وتنهية الوعى البيئي للهـرشدين السياحيين القائمسين على إدارة الشركات السياحية للحفاظ على الموارد 
الطبيعية والثقافية للمنطقة(ابراهيه ، .... ب)، وإتاحة الفرص لإيجاد مـجالات تعاون عابر للحدود بين مصر وليبيا والسودان، من خلال إعلان منطقة جبل العوينات كمنطقة تراث ثقايِّ مشترك بين الدول الثلاث ، ويتم إدارة تلك المحمية كهنتزه قومي ، يتضمن

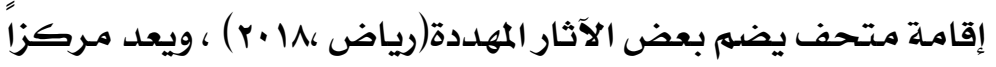
بيئياً لأهالي الواحات الداخلة ومـراقبة سلوك رحلات السفاري ومنتح التصاريح ونشر الوعى بأهمية المنطقة وإعداد برامـج موجهة للسكان المحليين للحفاظ على الموارد الطبيعية والمياه بهنطقة المحمية وإدارتها بالشراكة مـع المجتمـع المحلى(جريدة الشرق الأوسط ، $\cdot(r \cdot \cdots$

إعلان منطقة الجلف الكبير محمية طبيعية ووضعها على خريطة السياحة البيئية الدولية، وجعلها أحد مراكز الجذب السياحى يؤدى إلى عائد اجتمهاعى وإقتصـادى على المجتهــع المحلى وعلى العاملـين فى مـجال السياحة وخلق فرص عمل للسكان المحليين(ابراهيهم ، rا بr). تعد محميـة الجلف الكبير نواة السياحسة البيئيـة، وذلك بسبب وجود

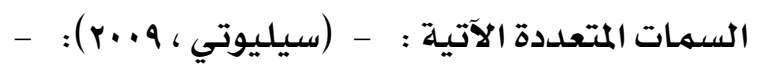
ا - تضهم سهولاً شـاسعة للكثبـان الرملية والكهوف التى تعود لعصور مـا قبل التتاريخ. 
أر تفعيل نظم الإدارة البيئية لمحميتي الجلف الكبير

ووادي الجمال بـ تنشيط السياحة البيئية

r - تضمى صخورًا رملية نوبية وفوهات بركانية قديمة ومناطق جبلية ووديانًا عميقة وسلاسل بحر الرمال الأعظم.

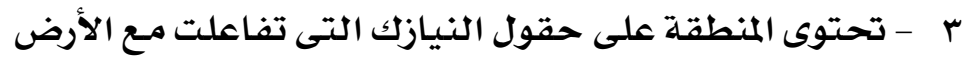

$$
\text { مكونة أكبر حقل نيازيك فى العالهم. }
$$

ع -توجد بها السيليكا الزجاجية الفريدة من نوعها.

ه - بها غطاء نباتي مكون من شجيرات عند جبل عبد المالك

$$
\text { والوديان المجاورة. }
$$

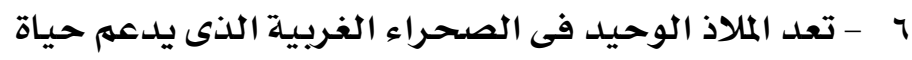
الحيوانات البرية آكلة العشب.

^ - بها طيور اللقلق والرخمة المصرية وصقر جراح والذين القمري وعصفور الجنة وأنواع أبو فصادة.

9 - ت تتمثل فيها الثدييات فى اليربوع الحر وثعلب الرمل والغزال والبقر الوحشي والكبش الأروى.

• 1 - تضم مجموعة من الأودية التى تحتوى على تراث ثقافة

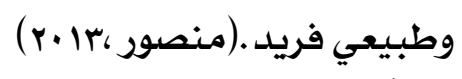

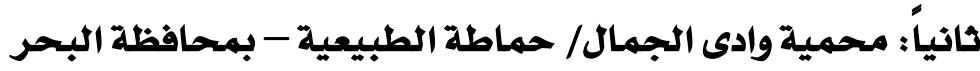

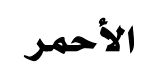

نظراً لأهمية هذه المنطقة وما تتعرض له من ضغوط ومتغيرات كثيرة مثل الاستخدام غير المنظم للمناطق الساحلية ، وعمليات تغيير خط الشاطئ واحتمالات التلوث والأنثطة السياحية 
والتعدينية غير المرثدة والصيد والرعى الجائر وقطع الأثجار والتفحيه، علاوة على الإضرار بالتراث الثقافى والحضارى ، فقد تم إعلان محميلة وادى الجمال - حماطة بمـحافظة البحر الأحمر محمية طبيعية لحماية الثروات الطبيعية والتراث النادر بها،

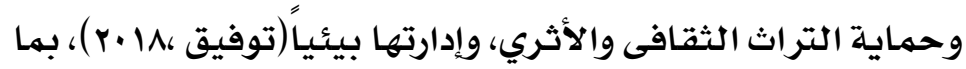
يحقق الاستخدام المستدام للهوارد وتعظيهم استفادة سكان المنطقة منها اقتصـاديا واجتمـاعيا ، علاوة على تفعيل التزامات مصر نحو الاتفاقيات الدولية المتعلقة بالحفاظ على التنوع البيولوجى، وزيادة

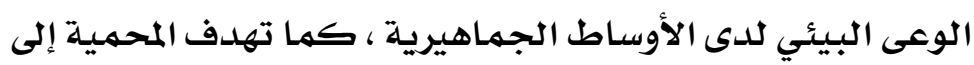
صون وإدارة تلك الموارد الطبيعية فى نظام بيئي متكامل ، وتشجيـع الاستخدام المستدام لهذه الموارد، وتعظيم الاستفادة من الظروف الطبيعية، والتخطيط الإقليمي لتنوع استغلال الأرض على ساحل البحر الأحمر ، حتى يتحقق زيادة العائد الاقتصادي للهنطقة والحفاظ على التقاليد الثقافية للسكان المحليين( سالم ، ع . . ). و تتمتحع المحمية بمقومات بيئية وجمالية وعلمية وثقافية فريدة ومتميزة للتراث الطبيعي بهصر؛ تتمثل العناصر الطبيعية فى المجتهعات النباتية الفريدة المنتشرة بها ،كما أن الوادي يضهم عديدا من الأنواع النادرة والمهددة بالانقراض من النباتات والحيوانات ، بالإضافة لتجمعات المانجروف الممتدة على طول سواحل المنطقة ، وأفضل الشعاب المرجانية والحشائش البـحرية التى هى مأوى لبعض 
أر تفعيل نظم الإدارة البيئية لمحميتي الجلف الكبير

ووادي الجمال بـ تنشيط السياحة البيئية

من الكائنات البحرية مثثل عروس البـحر والسـلاحف البحريـة وبيئة مناسبة لتكاثر الأسماك واللافقاريات ، وكل هذا يلعب دوراً كبيراً منيل

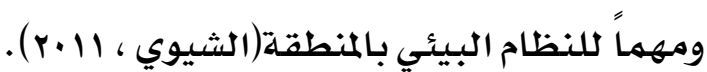
تتوافر بالمنطقة التكوينات الجيولوجية الفريدة ، وتزخر بالخامات التعدينية ذات القيمـة الاقتصداديـة الغنية مثل الزمـرد وأحجار الزينـة والفلسبار والكوارتز والرصاص والمنجنيز والذهب ، ويتهثل التراث الحضاري فى آثار ما قبل التاريخ من رسومـات صخرية تسجل أنشطة للإنسـان فى تلك الحقبـة التاريخية ، كما أنها تضهم تحت ثراها رفات العارف بالله أبى الحسن الشاذلى والذى أصبع مزاراً سياحياً

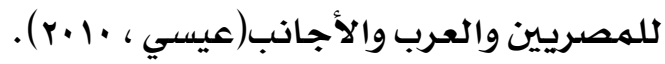

\section{الدراسة الميدانية :}

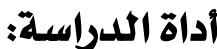

اعتهدت الدراسـة علي المنهج الاحصـائي عن طريق توزيـع استهمارات

المقابلات الشخصية علي عينه الدراسة لتكون الوسيلة الرئيسية لجمـع البيانات الميدانية بهدف تحقيق أهداف الدراسـة، واختبـار صحة فروض الدراسلة، ولتحقيق ذلك فقد تم تصميهم ثلاث استمارت مقابلة شخصية ؛ وجهت الأولى إلى مـديري محمـيتي الجلف الكبير ووادى الجمال ، ووجهت الثانية إلى الخبر اء السياحيين ، ووجهت الثالثة إلى الخبر اء البيئيين على النحو الآتي: I - استمارة مقابلات شخصية للخبر اء السياحيين: 
صمهمت استمارة الاستبيـان على شكل أسئلة موضوعية مكتوبة، حيث يقوم الخبير بالإجابة على الأسئلة الموضوعية التي شملت ( (1) أسئلة لكل منها، بهدف التعرف على آراء الخبر اء السياحيين واتجاهاتهم فيهـا يتعلق بأثر تفعيل نظم الإدارة البيئية لمحميتي الجلف الكبير ووادي الجمال يْ تنشيط السياحة البيئيـة. r صمهت استمارة الاستبيان على شكل أسئلة موضوعية مكتوبة، حيث يقوم الخبير بالاجابة على الأسئلة الموضوعية التي شملت ( (1) أسئلة لكل منها، بهدف التعرف على أراء الخبر اء البيئيين واتجاهاتهم فيها يتعلق بأثر تفعيل نظم الإدارة البيئية لمحميتي الجلف الكبير ووادي الجمال يْ تنشيط السياحة البيئية. r -استمارة مقابلات شخصية لمديري محميتى الجلف الكبير ووادى

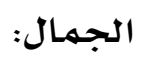

صمهمت استمارة الاستبيان على شكل أسئلة موضوعية مكتوبة ؛ حيث يقوم مدير المحمية بالإجابة على الأسئلة، وقد تكونت استمارة

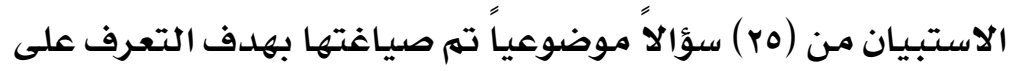
آراء مديري المحميتين واتجاهاتهم عن أثر تفعيل نظم الإدارة البيئيـة لمحميتي الجلف الكبير ووادي الجمال يخ تنشيط السياحة البيئية. اختبار هصحة فروض الدراسلة: 
أر تفعيل نظم الإدارة البيئية لمحميتي الجلف الكبير

ووادي الجمال بـ تنشيط السياحة البيئية

1

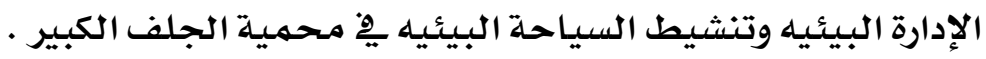

r ب - rين من تحليل عينة الدراسة وجود دلاله احصائية بين نظم

الإدارة البيئيه وتنشيط السياحة البيئيه هِّ محمية وادي الجمال .

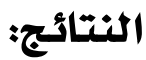

وفيما يأتي عرض تفصيلي لنتائج الدراسة التي تم التوصل إليها :

\section{أولاً : آراء مديري المحيميتين}

- إن نظام الاداره البيئية هو نظام إدارة ضروري ولا غني عنه داخل

المحميات، وذلك من خلال تحديد المناطق الحرجة التي تحتاج إلى

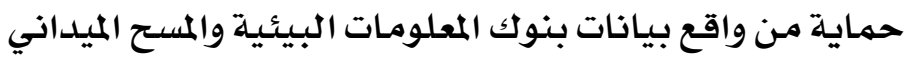

كلأنواع الحية.

-السبب الرئيسي لتبني نظم الادارة البيئية داخل المحمية هو

الحفاظ على استدامـة الموارد البيئية للأجيال القادمـة مـع الاستغلال الأمثل لتلك الموارد، ويرتبط ذلك بالسبب الرئيسي لإنشاء المحمية وهو الحفاظ على المناطق التي تحتوى على أنواع من الكائنات الحية سواء أكانت نباتية أم حيوانية أم تكوينات أثرية أم تراكيب جيولوجية نادرة، وصيانة الموارد الحية والحفاظ على العمليات البيئية التي ترتبط باستهرارية الحياة وبقاء الإنسان.

-السياسة البيئية داخل المحمية ليست موثقة ومعلنة لدى جميع

الموظفين بالصورة الكاملة ؛ويرجع ذلك إلى وجود ضعف يِّ 
التنسيق والمتابعة المرافقة لعمليات التتفيذ، ومـن ثم الرقابة والتقويم لرصد نقاط الضعف والانحرافات.

- المحميتان أساس الحفاظ على الموارد الحية وغير الحية ، والمحافظة على صححة العمليات البيئية . -إن تفعيل نظم الإدارة البيئية داخل المحمية يؤدى بالفعل إلى تنشيط السياحة البيئيـة ويرتبط ذلك بها جاء فى الإطار النظري مـن أن نظم الإدارة البيئية تتبنى سياسـة بيئية مناسبـة، وتتضهن الالتزام بالحد مـ التلوث، و تطبيق القوانين واللوائح والنظم البيئية الصادرة بالقوانين والتشريعات الخاصلة بالحفاظ على البيئة والمصادر الطبيعيـة وتنفيذها ومنـع التلوث بأنواعه المختلفـة. -أوضح مديرو المحميتين أن تفعيل نظم الإدارة البيئية داخل المحميـة يتمم من خلال قطاع حماية البيئة الطبيعية ، الذي يوفر الدعم اللازم لتتفيذ تلك النظمه . -تعد محمية الجلف الكبير من أكبر المحميات الطبيعية ِِِ مصر التي تحتوي علي كنوز عالمية وكهوف جبلية وصحراوية ومناظر طبيعية جعلتها منطقة جذب للسياح وهواة رحلات السفاري وتسلق الجبال ، وكان من أهم التحديات التي تواجه السياحة البيئية يِ محمية الجلف الكبير حاليا هي صعوبـة الحصول علي تصاريح

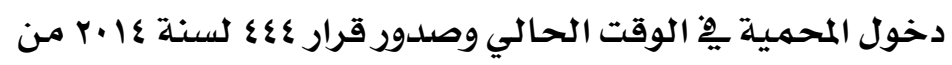
القوات المسلسحة بـاعتبارها منطقة محظورة. 
أر تفعيل نظم الإدارة البيئية لمحميتي الجلف الكبير

ووادي الجمال بـ تنشيط السياحة البيئية

\section{ثانياً :آراء الخبراء البيئيين}

-وجود تنسيق فعلى بين جهاز شئون البيئة وهيئة تنشيط السياحة

فِ تطبيق النظم الإدارة البيئية لتنشيط السياحة البيئية داخل

المحميات.

-إن جهاز شئون البيئة يقوم من خلال قطاع حماية البيئة بإدارة

محميـات مصر الطبيعية، وإعداد الدراسـات عن الوضـع البيئي

وصياغة الخطة القومية لحماية البيئة، والمشاركة يٍ إعداد

البرنامـج القومي للرصد البيئي وتنفيذه والاستفادة من بياناته.

وكذلك إعداد التقارير الدورية عن المؤثرات الرئيسية للوضع

البيئي ونشرها بصفة دوريـة. ووضـع برامـج التثقيف البيئي

للمواطنين والمعاونة ِِِ تنفيذها.

-إنه لتطبيق الإدارة البيئية بصورة ناجحة يحتاج الهيكل الإداري

للمـحميات إلى إعادة هيكلة وتطوير ، وذلك بـإنشاء هيئة لإدارة

المحميات ، وتطوير قدرات الباحثين وتكثيف الدورات التدريبية

لإكسابهم المهارات ، بالإضافة إلى دعم قدرات المحميات بالبنية

التحتيـة مـن المنشآت ومـراكز الزوار والأجهزة والمعدات التى تسهل

من تنفيذ برامـج إدارة المحميـة.

-إن جهاز شئون البيئة يقوم بلدعم محمهيتي وادي الجمال والجلف

الكبير من خلال دعم برامـج التعاون الإيطالي ، وتوفير البنية

التحتية لادارة المحميات ، والتعاقد مـع باحثين وتدريبهم ، وكذلك 


\section{مجلة كلية السياحة والفنادق - عدده- يوذيو ابrr}

توفير ميزانيـة سنوية لدعم إدارة المحمية فى تنفيذ برامـج الرصد

والحماية. وتوفير بعض فرص العهل للسكان المحليين بها، وكذلك

تنفيذ برامـج السياحة البيئية فى محمية وادى الجمال وتدريب

السكان المحليين لتزويد الدخل.

- يهكن الاعتهاد على موارد الطاقة النظيفة والمتجددة بهناطق

المحميات وخاصة الطاقة الشمسية ، فمعظم المحميات تقع فى هـ

مناطق صحراوية تتسهم بزيادة معدلات الاشعـاع الشهسي لها ، أما المعوقات فتتمثل فى عدم توفر ميزانية نفقات إيراديه فى بعض المحميات، وتحتاج وحدات الطاقة الشمسية المتجددة للصيانة الدورة ، بالإضافة إلى معوقات الروتين فى استخدام مصدادر الطاقة البديلة. -يهكن دعم أو تطبيق مفهوم نظم الإدارة البيئية فى المحميات من

خلال جهاز شئون البيئة وقطاع حمايـة الطبيعية.

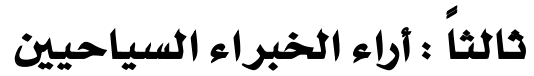

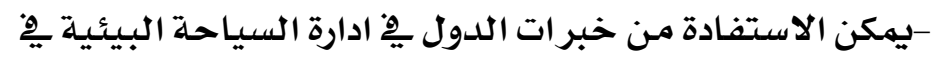

المحميات وتفعيلها عن طريق تشجيع التعاون الدولي وتبادل

الخبر ات البيئية وكذلك تفعيل دور الصناديق المانحة لدعم

مشاريـع البيئة.

-وجود خطة مستقبلية لتنهية وتنشيط السياحة البيئية

بالمحميات قامت بإعدادها وزارة البيئة تحت عنوان خطة تنهية

وتنشيط السياحة البيئة والتي ارتكزت علي عدة محاور أهمها رفع 
أر تفعيل نظم الإدارة البيئية لمحميتي الجلف الكبير

ووادي الجمال بـ تنشيط السياحة البيئية

كفاءة البنية الأسـاسية والإدارة الرثيدة لأصول الموارد الطبيعية لتنشيط السياحة البيئة ولدعم الاقتصساد وزيادة التنافسية وخلق فرص عمل جديدة.

- أهم الأنشطة السياحية ِِِ محمية الجلف الكبير هى السفاري وتسلق الجبال ومشاهدة المناظر الطبيعية الخلابة وزيارة الكهوف التي تحكي حياة إنسـان ما قبل التاريخ بها تحويـه هذه الكهوف من رسومات ونقوشات وكذلك منطقة السيلكا الزجاجية وهي تكوين فريـ من نوعه.

-وجود دور للإعلام مِ تنشيط السياحة البيئية داخل المحميات

حيث تتجلي أهمية الإعلام فِ كونه يساعد علي دفـع الجمهور ـِ الانخراط يِ عملية التخطيط واتخاذ القراروكذلك تعميهم الوعي البيئي للحفاظ علي الموارد الطبيعية وكذلك تسليط الضوء علي أهم المناطق السياحية داخل المحميات.

-ابراز دوروزارة الثقافة ومنظهي البر امـج السياحية يِّ تنشيط السياحة البيئية للهحميات عن طريق عمل مسابقات عن السياحة البيئية بالمحميات الطبيعيـة والترويج لها إعلاميا، وإبراز دور السياحة البيئيـة يِّ دعم الاقتصاد وخلق فرص عمل جديدة ووضـع مناطق السياحة البيئية يِ المحميات الطبيعية ضهمن أهم المزارات علي أجندة مقدمي البر امـج السياحية ، وإنتاج أفلام عن الصحاري المصريـة وإعداد برامجج تلفزيونية وإذاعية وأفلام وثائقية ومقابلات 
شخصية ، وعمل مسابقات عن التصوير الفوتوغرايِّ واللوحات الزيتية ، وإعداد مطبوعات عن الصحاري والمغارات والكهوف ومستلزمات رحلات السفاري يِ المحميات الطبيعية. -قيام بعض الأجهزة غير الرسهية والجمعيات الأهلية ِِِ دعم تطبيق نظم الادارة البيئية للمحميات، مـن خلال المشاركة فى تنفيذ برامـج الرصد البيئي والتوعية البيئية بالمحميات ودعمم قدرات سكان بعض المحميات بيئياً واقتصادياً. -وجود بعض المعوقات التي تواجه تطبيق عملية الإدارة البيئية فى المحميات منها مشكلات إداريـة ومـاليـة وتسرب الكفاءات وقلمة العاملين بها، وضعف الإمكانات المتاحة والتجهيزات فِ المحميات الطبيعية فضلا عن ضعف عمليات التسويق المحلى والدولي للهمحيات الطبيعية.

-تفتقد القوانين والتشريعات البيئية إلى مواكبة التطورات

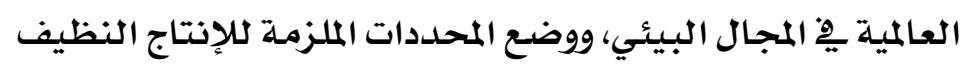
والصديق للبيئة، من خلال دمـج المواصفات البيئية فى المواصفات القياسية للمنتجات المختلفة .

-تفتقد الإدارة البيئية إلى توفر قاعدة معلومات بيئية كاملـة ودقيقة يعتمدد عليها صـانعو القرار البيئي من أجل اتخاذ الإجـراءات المناسبة لحماية البيئة . 
أر تفعيل نظم الإدارة البيئية لمحميتي الجلف الكبير

ووادي الجمال بـ تنشيط السياحة البيئية

-عدم تخصيص أدوات تعالج المشاكل البيئية يِّ المحميات بشكل

غير مـركزي، فمركزية الإدارة وضرورة اتخاذ القرار بالنسبـة للمشاكل المواجهة على مستوى مركزي، يشكل عبئًا على الإدارة العليا يِ المحميات، ويؤدى إلى تأجيل حل المثاكل المهمهة. -قلة المنظمات الأهلية غير الرسمية المهتمـة بالبيئة، والتى تلعب

دورا كبيرا فى الدفاع عن القضايا البيئية والحفاظ عليها. -الحفاظ على البيئة أسـاس بقاء السياحة واستهـرارها على المدي البعيد ، فالسياسـات السياحية لابد وأن تتبني ، بجانب الاعتبارات الاقتصادية ، الاعتبارات البيئية أيضاً للحفاظ على البيئة . -نقص الموارد البشريـة المتخصصصة فى مجال البيئة وحمايتها، والتى تكون المسئولة عن وضع السياسـات والتوجهات والأدوات والوسائل والمقاييس والمعايير البيئية الخاصلة بحمايـة البيئة. - نقص الإمكانيات المالية والتمويلية المخصصة للهشروعات البيئيـة الدفاعية والوقائية والموجهة لحماية البيئة والموارد البيئيـة وترثيد استخدامها والتى تعزز من قدرة وفاعلية وتأثير الإدارة البيئة -ضعف التجهيزات يِ المحميات لاسيما وجود دليل إرشادي للإدارة البيئية ، كما يوجد عجز يِّ مراكز البحث العلهي داخل المحميات ومعامل المراقبـة داخل المحميـات. 
-تفتقد المحميات إلى توفر مـراكز الزوار و النزل البيئية السياحية والمخيمات والمعسكرات البيئية داخل المحميات.

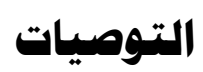

بناء على مـا أسفرت عنـه هذه الدراسـة من نتائج تم التوصل إلى

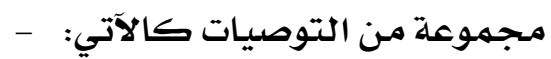
أولاً : توصيات موجهة إلى جهاز شئون البيئة :

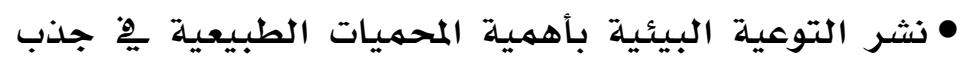
الحركة السياحية وتنشيط السياحة البيئية على مستوى السكان المحليين. •وضع المحميات الطبيعية على خريطة السياحة المصرية وإدراج الرحلات البرية والسفارى يِّائمة البرامـج السياحية التى

$$
\text { تقدمها الشركات السياحية. }
$$

•وضـع دليل إرثادي لبرامـج السياحة البيئية بالمحميات الطبيعية من أجل تنشيط حركة السياحة البيئية فى حدود القدرة الاستيعابية للمهحميات. •تزويد المحميات بالأجهزة والمعدات التي تسههم فى عملية الرصد البيئي لمناطق السياحة البيئية ومعامل التقييهم

$$
\text { والدراسة. }
$$

• العمل على إدراج مواقع آثار مـا قبل التاريخخ بهحميلة الجلف

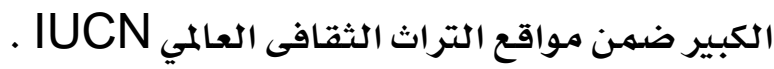


• العمل على إدراج مححمية وادي الجمال ضمن قائمـة المحميات

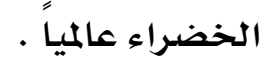

• تشجيـع التعاون مـع الجهات البحثية العالميلة والجهات المانحة

$$
\text { فى إجراء دراسات بيئية بمواقع المحميات. }
$$

• إعادة فتح محمية الجلف الكبير لزيارة السائحين وتسهيل إجراءات الحصول على تراخيص وفق الضوابط القانونية

$$
\text { والأمنية . }
$$

ثانياً : توصيات موجهة للمديرين :

إعداد برامج توعية بيئية موجهة إلى زوار المحميات الطبيعية للحفاظ على الموارد الطبيعية والثقافية يِ المحميات.

تطوير الهيكل الإداري للهحميات الطبيعية، وسد العجز فى الموارد البشرية والتخصصدات غير الموجودة.

\section{المراجع}

\section{|المراجع باللغة العربية:}

الحبشي ، علاء علوي (Y.r.r) : السياحة البيئية كمدخل لتطوير الريف المصري : إحياء التراث العمراني على ضفاف ترعة الباجوريـة بهحافظة المنوفيـة ، كليـة الهندسـة ، جامعة مدينة السـادات ، مدينة السـادات ، ج.م.ع.

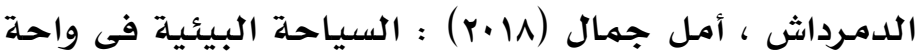
سيوة ، مـلـة البحث العلهي فى الآداب ، العدد 19 ، الجزء ب ، 
كلية البنات للآداب والعلوم والتربية ، جامعة عين شمس ،

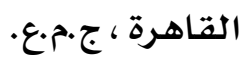

البعقوبي ،ناصر محمود عوض (r.lV) : الاثر الاجتماعي والسلوكي المتبادل بين سكان مناطق المحميات الطبيعية والعاملين والزائرين وفقاً لوظيفة وأهداف المحميات ، وسيادئة ماجستير غير منشورة ، معهد الدراسات والبحوث البيئية ، جامعة عين شمس ، القاهرة، ج.م.ع. إبراهيه، محمد إبراهيم محمد ( (.... ): المحميات الطبيعية والتنوع البيولوجى فى مصر، مجلة أسيوط للدراسات البيئية،

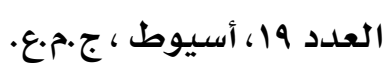

إبراهيهم ، محمد إبراهيه محمد ( r ب r) : المحميات الطبيعية فى مصر (القوانين والتشريعات والاتفاقيات المتعلقة بها) قطاع حماية الطبيعة، القاهرة ، ج.م.ع. إبراهيه، وفاء زكي (ج..r) : دور السياحة فى التتمية السياحية ، المكتبـة الجامعيـة الحديثة ، القاهرة، ج.م.ع. إبراهيهم ، محمد عبد الوكيل عطا (.r.r.) : تأثير وظيفة العمليات الخضراء على التميز المؤسسي فى ظل الدور الوسيط للمسئولية الاجتماعية للشركات : دراسـة ميدانية فى الشركات الصناعية المصرية ، رسالة دكتوراه غير منشورة ، كلية التجارة ، جامعة بنها ، بنها ، ج.م.ع. 
اثرتفعيل نظم الإدارة البيئية لمحميتي الجلف الكبير

ووادي الجمال يُ تنشيط السياحة البيئية

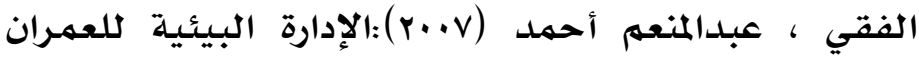

الحضري ، رسالة ماجستير غير منشورة ، كلية الهندسـة ،

جامعة عين شمس ، القاهرة ، ج.م.ع.

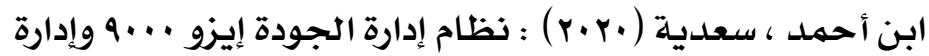

الجودة الشاملة : مفهومان متكاملان أم متعارضان ، مجلحة

مينا للدراسات الاقتصادية ، المجلد ب ، العدد ه ، المركز

الجامعي أحمد زبـانة غليزان ، معهد العلوم الاقتصـادية وعلوم

التيسير ، بغداد، العراق

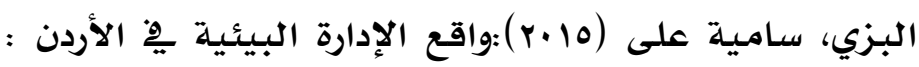

دراسـة ميدانية متوجهة نظر شاغلي الوظائف الإشرافية،

رسالة ماجستير غير منشورة، كلية الاقتصاد والعلوم الادارية،

جامعة اليرموك، الأردن.

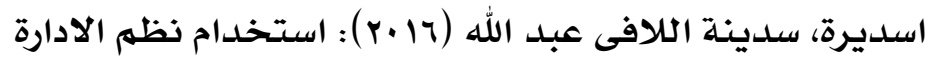

البيئية لمواجهة مشكلة التلوث البيئى فى قطاع الصناعة فى

ليبيا، رسالة ماجستير غير منشورة، معهد الدراسـات والبحوث

البيئيـة، جامعة عين شهس، القاهرة ، ج.م.ع.

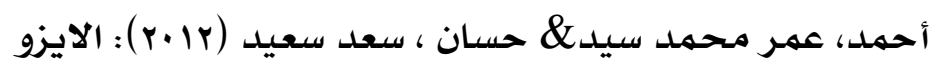

| 1ـا ودوره فى تفعيل السياحة البيئية بالتطبيق على على

منطقة الغردقة، ورقة بحث، كلية السياحة والفنادق، جامعة

المنوفيـة، المنوفيـة ، ج.م.ع. 
أحمد ، سهر عطية (·r.r. ) : تطبيق السلسة القياسية الأيزو | +. إ فى المحميات الطبيعية فى مصر وأثر ذلك على تقليل المخاطر البيئية ، مجلة كلية السياحة والفنادق ، جامعة

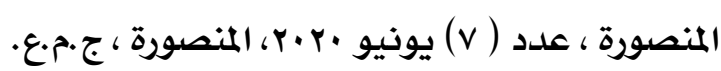
الشحات، نهال محمد فتحى ( r..vV) : برنامـج لتطبيق نظم الإدارة البيئية فى الصناعات الكبيرة لتحقيق التنمية المستدامة ، رسالة دكتوراه غير منشورة ، معهد الدراسات والبحوث البيئية ، جامعة عين شمس، القاهرة ، ج.م.ع. أحلام ، خان \& صوريـة ، وزاوي (·r) (ب) السياحة البيئية وأثرها على التنهية ِِ المناطق الريفية، بحث منشور، العدد السابع، يناير، كلية العلوم الاقتصادية والتجارية وعلوم التسيير، جامعة محمد خيضر بسكرة، الجزائر. آدم ، ندا حامدين ( 10 • ) : الأثر الاستراتيجي للإدارة البيئية في صناعة الأعلاف باستخدام المعايير الدولية لعام ع...r م منطقة صرمان ليبيا، رسالة ماجستير غير منشورة، معهد البحوث والدراسات الإستراتيجية ، جامعة أم درمان الإسـالامية، السودان. أبو عامود، إسماعيل ناصر (r. V ) : دعم السياحة البيئية مـن خلال الإدارة المستدامـة للغابات ، مجلة العلوم الإنسانية والاجتماعية ، المجلد ؟ع ، العدد ب ، عمان ، الأردن 
العجيلى ، عبدالله صبار عبود ( rا•r): مقومات السياحة

البيئية فى بحيرة الرزازة ،محلـة كلية الآداب ، جامعة بغداد ،

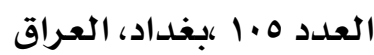

الشيوي، شيرين صبري السباعي (11+r): البيئات المحمية بشمال سيناء: دراسـة فى جغرافية البيئة، مجلة كلية التربية، جامعة المنصورة، العدد ه V، المنصورة ، ج.م.ع.

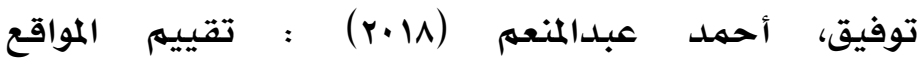
الجيومورفولوجية فى محمية وادى الجمال لتطوير السياحة الجيولوجية ، مجلة اتحاد الجامعات العربية للسياحة والضيافة ، المجلد 10 ، عدد خاص ، كلية السياحة والفنادق ، جامعة قناة السويس ، الإسماعيلية، ج.م.ع. جريدة الشرق الأوسط ( ^^•^) : الجلف الكبير.. يقصدها سياح يبحثون عن عبق الإنسان الأول، العدد سوی •ا ، ، القاهرة ، •? جلال ، سـامية محمد ( 0. • ) : نظام الإدارة البيئية المتكامل ، ط ا ، القاهرة ، المنظمة العربية للتنمية الإدارية ، القاهرة ، •ع.r.?. جهاز شئون البيئة (·r.r) : الموقع الرسمي لوزارة البيئة المصريـة ، القاهرة ، ج.م.ع. 


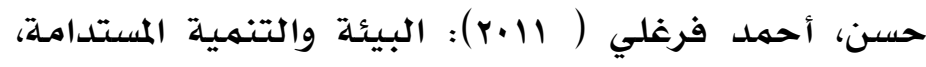
الإطار المعريٌ والتقييه المحاسبي، مركز تطوير الدراسات العليا والبحوث، جامعة القاهرة، القاهرة ، ج.م.ع.

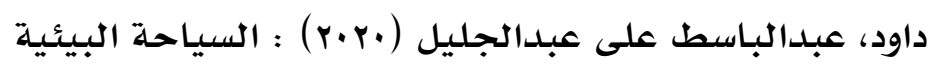
فى إقليهم الجبل الأخضر ودورها فى تحقيق التتميلة المستدامـة فى ليبيا ، المجلة العلمية لكلية السياحة والفنادق ، جامعة

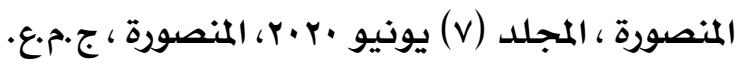
دراركه ، حمزة ومـروان، العلوان أبو رحمة ، ومصطفى

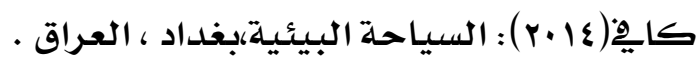
دهيهي، جابر \& بروث ، زين الدين (11 ب ) ): دور نظام الإدارة البيئية فِ تحسـين الأداء البيئي للمؤسسـات -دراسة حالة شركة الاسهنت الملتقى الدولي الثاني حول الأداء المتميز للهنظمات والحكومات، الطبعة الثانية: نمو المؤسسات والإقتصاديات بين تحقيق الأداء المالي وتحديات الأداء البيئي،المنعقد بجامعة ورقلة، الجزائر.

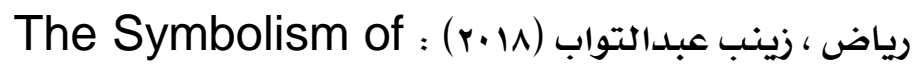
Hand Prints in Prehistoric Rock Arts in the Gilf Kebir, البحوث والدراسـات التاريخية ، كلية الآداب ، جامعة القاهرة ، القاهرة ، ج.م.ع. 
أر تفعيل نظم الإدارة البيئية لمحميتي الجلف الكبير

ووادي الجمال بـ تنشيط السياحة البيئية

زهير ، بوعكريف ( 17.1\%) : السياحة البيئية كآلية لدعم

تحقيق تنمية سياحية مستدامة : إيضاءات على بعض التجارب العربية ، مجلة التنمية الإقتصادية ، جامعة الشهيد

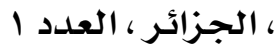

سلامة ، منى الباز محمد (·r.r) : أثر تطبيق نظام الادارة البيئية على الميزة التنافسية والريحية ، مجلة كلية التجارة ،

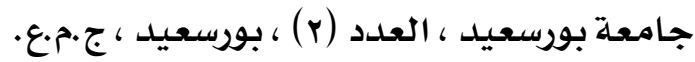
سالم ، عوض عبد المعبود (؟؟ب): المحميات الطبيعية والسياحة فى مصر: الحدود والقيمة فى ميزان حماية البيئة والاقتصاد البيئي، مجلة مركز البحوث الجغرافية والكارتوجرافية، جامعة المنوفية، العددا،، المنوفية ، ج.م.ع.

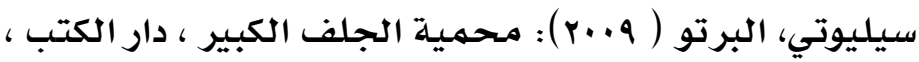

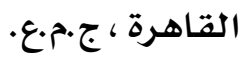
شجاع ، أسماء على ابراهيم (·r ·r ) : دور إدارة الجودة المتكاملة فى تحقيق التنمية المستدامـة للمحميات الطبيعية المصرية ، المجلة العلمية للدراسات التجارية والبيئية ، المجلد || ، العلدد 1 ، كلية التجارة ، جامعة قناة السويس ، الإسماعيلية، ج·م.ع.

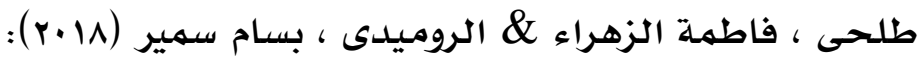
السياحة البيئية ودورها فى حماية البيئة فى ضوء الاستراتيجية الوطنية للسياحة البيئية فى مصر، مؤتمر دولي 
حول إشكالية البيئـة فى المجتهـع العربى بين الممارسـة والتتظير

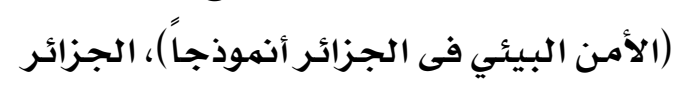

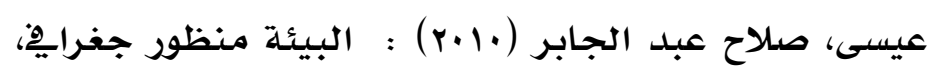
مطبوعات كلية الآداب، جامعة المنوفية، المنوفية ، ج.م.ع.

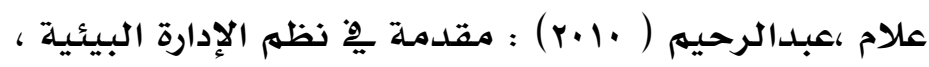
المنظمة العربية للتتهية الإدارية ، القاهرة ، ج.م.ع.

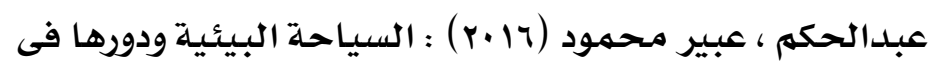
تحقيق التنمية السياحية المستدامة ،المجلة العلمية للاقتصاد والتجارة ، العدد r ، كلية التجارة ، جامعة عين شمس ،

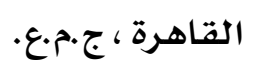
عوده ، رياض مححمد على ( rا.r) : السياحة البيئية وآثارية فى محافظة كريلاء واستثمارها فى تحقيق التنمية المستديهة ، مجلة البحوث الجغرافية ، كلية التربية للبنات جامعة الكوفة ، العراق ، العدد 11 ، الكوفة ، العراق . غرايبة ، خليفة مصطفى (r (r ) : السياحة البيئية، دار ناشري للنشر الالكتروني، عمان ، الأردن.

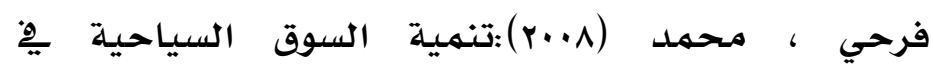
الجزائر،مجلة العلوم الاقتصسادية وعلوم التسيير، الجزائر، العدد IV ، المجلد r ، الجزائر . 
اثرتفعيل نظم الإدارة البيئية لمحميتي الجلف الكبير

ووادي الجمال يُ تنشيط السياحة البيئية

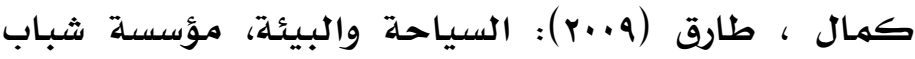
الجامعة، الإسكندريـة، ج·م·ع.

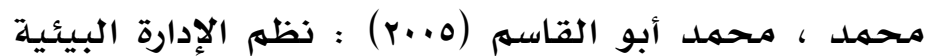
،مجلة أسيوط للدراسـات البيئية - العدد التاسـع والعشرون ،

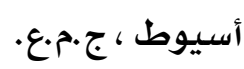

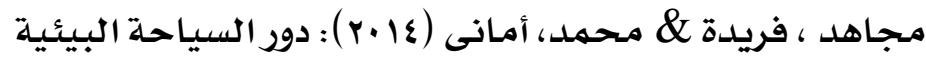
فى التنمية السياحية المستدامـة بهنطقة كينـج مريوط بالتطبيق على منشأتها الفندقية: دراسـة حالة، مجللة اتحاد الجامعات العربية للسياحة والضيافة، كلية السياحة والفنادق، جامعة قناة السويس، الإسماعيلية ، ج.م.ع.

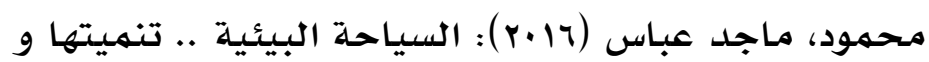
دور المحميات الطبيعية ، مكتبـة الأنجلو ، القاهرة ، ج.م.ع. منصور، نسرين السعيد (rا •r) : نهوذج مقترح لإدارة الأزمات الناتجة عن التغيرات المناخية المتوقعة فى بعض المحميات الطبيعية فى مصر ، رسالة دكتوراه غير منشورة ، معهد الدراسـات والبحوث البيئية ، جامعة عين شمس ، القاهرة ،

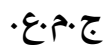

\section{r/ المراجع باللغة الأجنبية :}

- Ajlouni ,N.,(2011) : Ecotourism and Culture Landscape Conservation Bani Nami Wilderness 


\section{-}

Herbon, M.se Research un published, Faculty of Engineering, Birzeit University, Palestine.

- Manr, N. (2010): Economic Development \& Environmental Policy, Kegan Paul International, UK.

- Pandy.G.N.,(2007) : Environmental Management, Vikas Publishing House, New Delhi

- Uren, S., and Griffiths, E. (2000):Environmental management in construction, CIRIA, London.

- Grandoit, J. (2005). Tourism as a development tool in the Caribbean and the Environmental by Products the stresses on small island resources and viable remedies, Journal of Development and Social Transformation, vol. 2, no (2). 